\title{
LIBRE DESARROLLO DE LA PERSONALIDAD EN CAMBIO DE NOMBRE A PERSONA POR SEGUNDA VEZ EN COLOMBIA
}

\author{
Autores: Nelson Enrique Maury Palacio ${ }^{1}$ \\ Correspondencia en: nmauryp18@curnvirtual.edu.co
}

\section{RESUMEN.}

Se trata de establecer en el presente estudio, los precedentes jurídicos expresados por la Corte Constitucional, en la que permite el cambio de nombre a las personas por segunda vez, muy a pesar de estar establecido en el ordenamiento jurídico colombiano, que tal situación solo procede por una sola vez; en tanto la Corte decreta la inaplicación de un norma legal, con el Decreto 1260 de 1970, dándole paso triunfal a la singularidad de cada proyecto de vida individualmente considerado, desde la óptica de los derechos fundamentales estatuidos en la Carta del 91 y el libre desarrollo de la personalidad institucionalizado en el Artículo 16 de la norma superior.

\section{Palabras Claves}

Constitución, Derechos fundamentales, Proyecto de vida, Dignidad humana.

\section{ABSTRACT}

It is a question of establishing in the present study, the juridical precedents expressed by the Constitutional Court, in which the renaming allows to the persons for the second time, very in spite of being established in the juridical Colombian classification, that such a situation only proceeds for an alone time; while the Court decrees the laziness of one legal norma, with the Decree 1260 of 1970 , giving him triumphal step to the singularity of every individually considered project of life, from the optics of the rights fundamental estatuidos in the Letter of 91 and the free institutionalized development of the personality in the Article 16 of the top norm.

\section{Keywords}

Constitution, fundamental rights, project life, human dignity

\section{INTRODUCCIÓN}

Desde la entrada en vigencia de la novel Constitución del 91 se han venido desarrollado una serie de cambios sustanciales en el campo del Derecho, pero fundamentalmente en el Derecho Constitucional y por ende en los derechos fundamentales, institucionalizados en la Carta; si por ejemplo, el Artículo 16 de la

\footnotetext{
${ }^{1}$ Abogado. Secretario General del Honorable Concejo Municipal de Puerto Colombia
} 
Vol. 6, No. 1 Diciembre de 2014 pp. 17 - 30

Constitución Nacional, se enseña que "Todas las personas tienen derecho al libre desarrollo de su personalidad sin más limitaciones que las que imponen los derechos de los demás y el orden jurídico" (Colombia. Asamblea Nacional Constituyente, 1991). Así mismo en el Preámbulo de la norma superior, se destacan algunos elementos, como el de la obligación del Estado en

asegurar a sus integrantes la vida, la convivencia, el trabajo, la justicia, la igualdad, el conocimiento, la libertad y la paz, dentro de un marco jurídico, democrático y participativo que garantice un orden político, económico y social justo, y ...(1991).

Existe un interés en manifestar la opinión de los autores de este Artículo, partiendo del conocimiento de hechos, decisiones, análisis de distintas manifestaciones a las cuales está sujeto el ser humano, del ciudadano que con acciones constitucionales, han cambiado paulatinamente el rumbo de las instituciones políticas.

Académicamente se realiza un modesto aporte al debate dentro y fuera del claustro universitario, pues se trata de decirle a los pares de otros escenarios de la academia, que aunque conscientes del interés del Estado colombiano en dinamizar la implementación de un Estado Social de Derecho, permitiéndole a los asociados, determinar con libertad, cualquiera sea su proyecto de vida, bajo el criterio de dignidad humana, como elemento dogmático de la Constitución Política; resulta coherente, que el interés en el tema, se adecúa y ajusta perfectamente al contexto nacional, por ejemplo, se encuentran discursos muy conservadores, como el suscitado hace poco tiempo en el Congreso de la República de Colombia, en torno a una posición conservadora, sobre el tema del matrimonio igualitario, lo cual generó malestar en un sector de la población y por ende el pronunciamiento serio y contundente de muchas vertientes sociales con disimiles criterios. 
Hoy son múltiples, los pronunciamientos de la Corte Constitucional y de los organismos defensores de los Derechos Humanos, el hecho de haberle concedido al accionante la posibilidad de cambiar su nombre por segunda vez, aplicando normas de carácter legal, se configura como una fulgurante forma de garantizar derechos que antes no eran tenidos en cuenta y mucho menos cuando de individualizarlos, se trataba, como es el caso del cual se ocupa la Sentencia reguladora de la presente temática.

\section{MATERIALES Y MÉTODOS}

Los elementos materiales de los cuales se dispuso para el desarrollo del presente trabajo de línea jurisprudencial, fueron sin lugar a dudas las Sentencias dictadas por la Corte Constitucional, tales como la Sentencia T - 977 de 2012, Sentencia T- 1033 de 2008 y Sentencia T - 221 de 1994, en cuyo texto, se hace énfasis de manera reiterada en el derecho al libre desarrollo de la personalidad.

\section{RESULTADOS Y DISCUSIÓN}

Al análisis de las sentencias que se desglosan en la investigación y para que no quede ninguna duda, acerca de cuál es la verdadera intención de un verdadero interés del tema, se le agrega el trabajo de someterlas a un estudio axiológico, lo cual no es otra cosa, que el tratado de la naturaleza de valores o juicio valorativo que se ha sido extractado del contenido de la Sentencia T - 977 de 2012 y de la Sentencia 1033 de 2008, distinguiendo en cada una de ellas cuál es su fuerza vinculante o elementos implícitos que obviamente hacen parte de la ratio decidendi y contrario sensu, se hace mención de la obiter dicta, para cada caso jurisprudencial.

El Artículo 230 de la Constitución Política de Colombia, señala que: "Los jueces, en sus providencias, sólo están sometidos al imperio de la ley. La equidad, 
Vol. 6, No. 1 Diciembre de 2014 pp. 17 - 30

la jurisprudencia, los principios generales del Derecho y la doctrina son criterios auxiliares de la actividad judicial." (1991). Del mismo modo la Carta del 91, señala en el Artículo 4, lo siguiente:

La Constitución es norma de normas. En todo caso de incompatibilidad entre la Constitución y la ley u otra norma jurídica, se aplicarán las disposiciones constitucionales. Es deber de los nacionales y de los extranjeros en Colombia acatar la Constitución y las leyes, y respetar y obedecer a las autoridades (1991)

Es pues, hora de entrar analizar separadamente cada una de las Sentencias reguladoras del tema de este estudio.

\section{- Análisis estático de la Sentencia T - 977 de 2012.}

Los hechos de esta Sentencia afirman que un señor a quien por decisión de La Corte Constitucional, tiene por nombre XXX, en el año 2007 mediante escritura pública realizó cambio de nombre, porque deseaba ajustarlo a su "identidad religiosa". Prosigue el relato de los hechos, que un año más tarde, el accionante, “inició un proceso integral de construcción de una nueva identidad de género como mujer, pues a pesar de que fisiológicamente su cuerpo presenta características masculinas desde su nacimiento, sentí que mi sexo no correspondía a la construcción de identidad de género que deseaba" (Colombia. Corte Constitucional, 2012).

Tres años después, el accionante, impetró derecho de petición en la Notaría, solicitando el cambio de nombre por segunda vez, situación que fue negada por la entidad, fundamentando su negativa en el Artículo 94 del Decreto 1260 de 1970 (1970) el cual preceptúa, que en Colombia se permite cambio de nombre una sola vez. Con base en estos hechos, se interpone la acción constitucional de tutela y 
Vol. 6, No. 1 Diciembre de 2014 pp. 17 - 30

solicita al juez de amparo ordenar a la Notaria, adelantar el procedimiento correspondiente para el trámite de cambio de nombre, por segunda vez, con el aporte del acervo probatorio pertinente y conducente.

Esgrime también el actor, que la negativa de sus pretensiones, vulnera sus derechos al libre desarrollo de la personalidad constitucional y a la dignidad humana, puesto que se expone a burlas y tratos discriminatorios, "ya que cuando se expone públicamente el nombre que aparece en el documento de identidad dista a plena vista de [su] condición identitaria como mujer." Por lo cual desea obtener la tutela de sus derechos, para cambiar su nombre por un nombre de mujer. Tal situación, fue negada por los jueces constitucionales de primera y segunda instancia.

Sabiamente la Corte Constitucional, institucionalizada para la salvaguarda del bloque de constitucionalidad, expreso las siguientes consideraciones 0 fundamentos de derecho, con una fuerte fuerza vinculante extraordinaria (Corte Constitucional. sentencias T-532 de 1992 y C-221 de 1994.), cuando señaló: " Además, el pluralismo como principio constitucional (Artículo $1^{\circ}$ Constitución Nacional), así como el contenido normativo correspondiente a la autonomía personal (derecho de autonomía personal), cuya garantía se deriva, según la jurisprudencia de la Corte Constitucional, del derecho al libre desarrollo de la personalidad (Artículo 16 Constitución Nacional), del derecho de autodeterminación (Corte Constitucional. Sentencia T-124 de 1998), que lo trae vinculado en el Artículo 9 la Constitución Nacional) y del derecho de dignidad humana (Corte Constitucional. Sentencia C-355 de 2007), en el Articulo $1^{\circ}$ de la misma Constitución, soportan en buena medida la posibilidad de implementar proyectos de vida individuales con los objetivos más diversos que cada individuo pueda diseñar. 


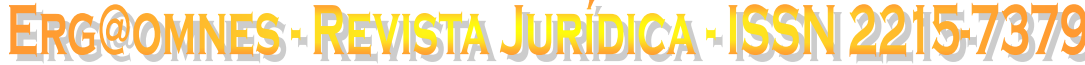

Vol. 6, No. 1 Diciembre de 2014 pp. 17 - 30

La consagración del pluralismo como pilar fundamental de la organización de la sociedad colombiana, implica la prevalencia de la autonomía (Corte Constitucional - Sentencia SU-337 de 1999), y así del respeto por las decisiones que dentro del orden legal tomen los individuos como seres libres.

Además, expresó la Corte que la entrada en vigencia del principio de organización pluralista (general) y del derecho a la autonomía personal o singularidad, se desprenden importantes principios que limitan el espacio de libertad de las personas. Es así que puede afirmarse que la competencia de las autoridades no tiene prima facie, el alcance de regular dimensión son aquellas conductas de las personas, que no obstruyan el goce pleno de otras personas, en cuanto a sus derechos se refiere. Así también se deduce de lo transcrito a continuación, sobre la obiter dicta de la sentencia aludida, al manifestar el Alto Tribunal:

Si bien lo anterior es suficiente para conceder el amparo, conviene señalar por último que si bien la persona demandante ejerció con anterioridad la facultad que otorga la ley para modificar el nombre con el fin de fijar su identidad personal, lo que en principio haría improcedente un nuevo cambio, esta Sala no puede desconocer que se trata de un caso excepcional en el que la aplicación inflexible de la restricción legal compromete el plan de vida de una persona que ha tomado medidas incluso de carácter quirúrgico para conseguir una determinada identidad...

Por último la corte, fundada en aspectos netamente jurídicos, profiere Sentencia, ordenando la protección de los derechos constitucionales del actor, revocando la sentencia proferida por el aquem y ordenado a la respectiva Notaría, inaplicar la norma de carácter legal, para proceder al cambio de nombre del accionante, por segunda vez. 


\section{- Análisis estático de la Sentencia 1033 de 2008}

En esta segunda Sentencia, que igualmente toca el tema central o eje del estudio, se trata de una Acción de Tutela, cuyo actor pretende se cambie su nombre por segunda vez, narrando los siguientes hechos: El accionante narra que, debido a su condición, decidió cambiar su nombre original masculino, por un nuevo nombre femenino. Adicionalmente, realizó diferentes tratamientos a nivel hormonal para obtener una apariencia más femenina.

Agrega que como consecuencia de esta novedosa orientación sexual personal, se vio inmerso en una vida de prostitución y degradación que lo hizo recapacitar sobre su futuro al punto de decidir dejar atrás la vida que llevaba para intentar la conformación de una familia y la consecución de un trabajo digno.

Como consecuencia de lo anterior, el actor solicitó a la Registraduría Nacional del Estado Civil, que le autorizara la posibilidad de retomar su nombre original, lo cual fue denegado.

El Tribunal Superior del Distrito Judicial de Cali, negó las pretensiones del accionante, en consideración a que en Colombia, solo procede el cambio de nombre a personas, por una sola vez (Colombia. Congreso de la República, 1970).

Consideró en su momento La Corte colombiana en la ratio decidendi de la Sentencia, que:

Dentro de los atributos de la personalidad, se encuentra el nombre que goza de naturaleza plural al ser i) un derecho fundamental inherente a todas las personas por el solo hecho de su existencia, ii) un signo distintivo que revela la personalidad del individuo y iii) una institución de policía que permite la identificación y evita la confusión de personalidades (Colombia. Corte Constitucional, 2008). 
Más adelante, en el mismo texto, el Alto Organismo subraya:

Bajo este entendido, la fijación del nombre, como atributo de la personalidad, resulta determinante para el libre desarrollo del plan de vida individual y para la realización del derecho a la identidad, en la medida en que, como se dijo anteriormente, aquél constituye el signo distintivo del sujeto en el plano relacional (2008).

Con estos argumentos La Corte Constitucional, decidió, tutelar las pretensiones del actor, ordenado a la Registraduria Nacional, proceder en un tiempo perentorio, al cambio de nombre del accionante, por segunda vez, asignándole el nombre que originalmente éste tenía.

\section{CONCLUSIONES}

Colombia ha vendido cambiando paulatinamente sus costumbres, su ordenamiento jurídico y se encuentra posicionada en los derroteros de las culturas democráticas más modernas del universo. Eso significa un gran avance para más de cuarenta millones de colombianos.

Estos cambios conducen entonces sin vacilaciones a decir hoy por hoy, que se está frente a procesos de renovación, en las costumbres jurídicas en las que impera la condición fundamental de lo social, la persona humana, y sin exageraciones ni vacilaciones se ha pasado de una vez por todas de un Estado de Derecho a un Estado Social de Derechos, en donde, visto desde la óptica de los Derechos Humanos, del Derecho Internacional Humanitario, de instituciones defensoras de estos derechos, de sociedades aglutinadas como grupos reales de poder, que incursionan en la vida constitucional, para hacer valer sus derechos 
Vol. 6, No. 1 Diciembre de 2014 pp. 17 - 30

prevaleciendo el derecho social, no solo para hechos de carácter general, sino en eventos singulares como ha sido planteado en la Sentencia T- 977 de 2012.

A criterio personal el cambio de nombre a personas por segunda vez, ordenada por la honorable Corte Constitucional en reiteradas Sentencias, es una muestra fehaciente de que se está avanzando en materia constitucional. En esa dirección se está adelantando una verdadera construcción jurídica de frente a los derechos fundamentales y los principios de un Estado Social de Derechos estatuidos en la Carta Política del 91.

\section{BIBLIOGRAFÍA}

Bernal C. (2006). Metodología de la investigación. México: Pearson Educación

Colombia. Asamblea Nacional Constituyente. (2001). Constitucional Política de Colombia, 1991. Disponible en:

http://www.alcaldiabogota.gov.co/sisjur/normas/Norma1.jsp?i=4125

Colombia. Presidencia de la República. (1970). Decreto 1260 (27, Julio, 1970). Disponible en:

http://ramajudicial.gov.co/csj//publicaciones/index/subcategoria/367/799/RedIberoamericana-de-Escuelas-Judiciales

Colombia. Corte Constitucional de Colombia. (2012). Sentencia T- 977 de 22 de noviembre de 2012. Expediente T- 3480973.

Colombia. Corte Constitucional de Colombia (1994). Sentencia C-221 de 5 de Mayo de1994. Expediente No. D- 429.

Colombia. Corte Constitucional de Colombia (2008). Sentencia T-1033 de 17 de Octubre de 2008. Expediente T-1.842.664. 


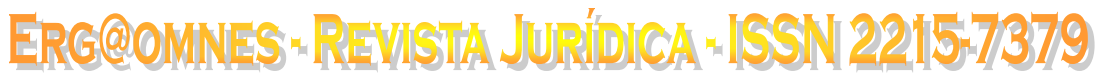 \\ Vol. 6, No. 1 Diciembre de 2014 pp. 17 - 30}

López D. (2006). El derecho de los jueces. Bogotá: Legis 